\title{
Utilization of Intrathecal Midazolam for the Prevention of Nausea and Vomiting In Caesarean Section under Spinal Anaesthesia- A Prospective Study
}

\author{
Naitik B. Patel ${ }^{1}$ \\ ${ }^{1}$ Associate Professor, Department of Anesthesia, Pacific Institute of Medical Sciences, Ambua Road, Village Umarda, Girwa, Udaipur.
}

\section{Abstract}

Background: Antiemetic effect of midazolam could be explained by its action at the chemoreceptor trigger zone reducing synthesis, release and postsynaptic effect of dopamine. Administration of low dose of iv midazolam as premedication prior to caesarean section reduces anxiety of mother, without any adverse effect on newborn. Therefore present study was done with an aim to evaluate the effect of intratechal midazolam for reduction in incidence of intraoperative and immediate postoperative nausea and vomiting. Subjects and Methods: Present prospective study was performed in the department of Anesthesia, Pacific institute of Medical Science, Udaipur, Rajasthan for the period of one year. The patients received $10 \mathrm{mg}(2.0 \mathrm{ml})$ of $0.5 \%$ hyperbaric bupivacaine combined with $2 \mathrm{mg}(0.4 \mathrm{ml})$ midazolam in Group A as a study group and $10 \mathrm{mg}(2.0 \mathrm{ml})$ of $0.5 \%$ hyperbaric bupivacaine combined with $0.4 \mathrm{ml}$ normal saline in Group B as a control group. The patients were evaluated for possible adverse effects, including sedation, respiratory depression, nausea and vomiting, by a researcher who was blinded to the details of the study until 3 hours after the end of surgery. Results: $28.8 \%$ of patients in control group had nausea as compared to $17.7 \%$ of patients in midazolam group. Similarly, $15.5 \%$ of the patients in control group had retching as compared to $2.2 \%$ in midazolam group. $2.2 \%$ of patients in midazolam group had frank vomiting where as in control group, $18.33 \%$ of the patients had vomiting. Difference between both groups regarding emetic symptoms was found to be significant statistically ( $\mathrm{p} \leq 0.05$ ). Conclusion: Intrathecal midazolam $2 \mathrm{mg}$ with $0.5 \%$ hyperbaric bupivacaine in the subarachnoid block was effective significantly to prevent nausea and vomiting in parturient undergoing caesarean section under spinal anaesthesia.

Keywords: midazolam, nausea, spinal anaesthesia, vomiting.

Corresponding Author: Dr Naitik B. Patel, Associate Professor, Department of Anesthesia, Pacific Institute of Medical Sciences, Ambua Road, Village Umarda, Girwa, Udaipur, - 313015 (Rajasthan).

Received: August 2019

Accepted: August 2019

\section{Introduction}

The most commonly used anesthesia technique in cesarean sections is spinal anesthesia, this is due to its economical value, the administration is easy to execute, very effective, the rate of failure is very low, there is no systemic local anesthetic toxicity and the most important factor that it has a high rate of maternal satisfaction. Nausea and vomiting during spinal anesthesia for elective cesarean delivery is a common finding and may occur in up to $66 \%$ of patients. ${ }^{[1]}$ The usual drugs used for prevention or treatment of this important adverse effect have adverse effects such as intense sedation, dystonic reactions, restlessness, and extrapyramidal symptoms. ${ }^{[2]}$ The reported incidence of nausea and vomiting during caesarean performed under regional anaesthesia varies from $50 \%$ to $80 \%$ when no prophylactic antiemetic is given. ${ }^{[3,4]}$ Therefore, use of prophylactic antiemetics in parturients undergoing caesarean delivery is recommended by some authors. ${ }^{[5,6]}$

Numbers of treatments have been introduced in order to reduce post-operative nausea and vomiting (PONV), such as 5-HT3 antagonists (ondansetron and granisetron), dopamine receptor antagonists, and antihistamine drugs. However, each of these treatments is associated with critical limiting factors, namely cost with 5- HT3 antagonists, extrapyramidal symptoms with dopamine receptor antagonists, excessive sedation and tachycardia with antihistamine drugs. ${ }^{[7]}$ Some authors used infusion of propofol with a subhypnotic dose $(1.0 \mathrm{mg} / \mathrm{kg} / \mathrm{hr})$ and found that it was effective in the prevention of emetic symptoms during spinal anaesthesia for caesarean section. ${ }^{[8]}$

Midazolam (benzodiazepine) is water soluble and a potent short acting drug. It has been used for potentiating the analgesic effect of local anaesthetic in neuro-axial blockade. It is a short-acting benzodiazepine with a rapid onset of action. In recent years, midazolam has been reported to be effective for prophylaxis of PONV by bolus administration before or after induction of anaesthesia or postoperative continuous infusion. ${ }^{[9-11]}$ Its antinociceptive effect is mediated through benzodiazepine-GABA receptor complex within the spinal cord. It acts by reduces excitatory GABA- 
mediated neurotransmission in interneurons \& increases the threshold for pain. Antiemetic effect of midazolam could be explained by its action at the chemoreceptor trigger zone reducing synthesis, release and postsynaptic effect of dopamine. ${ }^{[12]}$ Administration of low dose of iv midazolam as premedication prior to caesarean section reduces anxiety of mother ,without any adverse effect on newborn. ${ }^{[13]}$ As traditional antiemetic are associated with side effects mentioned above, to find an alternative approach to antiemetic therapy this prospective, randomized, double blind study was planned by using midazolam $(2 \mathrm{mg})$ as an adjuvant to bupivacaine in spinal anaesthesia. Therefore present study was done with an aim to evaluate the effect of intratechal midazolam for reduction in incidence of intraoperative and immediate postoperative nausea and vomiting.

\section{Subjects and Methods}

Present prospective study was performed in the department of Anesthesia, Pacific institute of Medical Science, Udaipur, Rajasthan for the period of one year. Approval was taken from the Institutional Human Ethics Committee before commencement of the study. Written expressed consent was taken from the participants. Patients with physical status I and II scheduled for elective term cesarean section under spinal anesthesia and they were included in this study. Who had obstetric complications or evidence of foetal compromise or patients who had gastrointestinal disease or administration of antiemetic medication in the previous 24 hours were excluded. Time taken and handling of viscera during cesarean section is more in multigravida with previous cesarean section which may trigger pain and emetic symptoms, thus we have included only primary gravida women. Ninety patients were divided into two groups (45 each) by random sampling methods.

Before beginning spinal anesthesia, patients were instructed on the use of the visual analog scale evaluation. Monitoring included continuous ECG, noninvasive blood pressure, and pulse oximetry. All patients were fasted overnight and received premedication with ranitidine $150 \mathrm{mg}$ orally the night before and 2 hours prior to surgery. After arrival in the operating room and intravenous (IV) access, $15 \mathrm{ml} / \mathrm{Kg}$ of Ringer solution with an addition of $10 \mathrm{mg}$ ephedrine was infused within 10 minutes before the initiation of the spinal block.

Spinal anesthesia was performed at L3-L4 interspaces with 25G Quincke needle in left lateral position. The patients received $10 \mathrm{mg}(2.0 \mathrm{ml})$ of $0.5 \%$ hyperbaric bupivacaine combined with $2 \mathrm{mg}(0.4 \mathrm{ml})$ midazolam in Group A as a study group and $10 \mathrm{mg}(2.0 \mathrm{ml})$ of $0.5 \%$ hyperbaric bupivacaine combined with $0.4 \mathrm{ml}$ normal saline in Group B as a control group. On completion of spinal injection the patient was placed in the supine position with left uterine displacement. Oxygen (3 L/min) was administered via facemask. Cardio respiratory parameters were monitored continuously and recordings were made every 5 minute till the end of surgery. Postoperatively 30 minutes interval up to 6 hour in recovery room. Intraoperatively and postoperatively incidence of bradycardia was treated with
$0.6 \mathrm{mg}$ of injection atropine iv. Hypotension was treated by increasing the rate of intravenous fluid administration, and by inj. mephentermine 3 to $6 \mathrm{mg}$ iv.

After delivery of the baby and clamping of the umbilical cord, a 10 I.U.of inj. oxytocin was given iv. APGAR score of all the babies with recordings at 1 and 5 minutes. Intraoperative and post delivery emetic symptoms till 6 hours were recorded by direct questioning by an anesthesiologist. The patients were evaluated for possible adverse effects, including sedation, respiratory depression, nausea and vomiting, by a researcher who was blinded to the details of the study until 3 hours after the end of surgery.

Statistical analysis

The data was coded and entered into Microsoft Excel spreadsheet. Analysis was done using SPSS version 15 (SPSS Inc. Chicago, IL, USA) Windows software program. The variables were assessed for normality using the Kolmogorov-Smirnov test. Descriptive statistics were calculated.

\section{Results}

[Table 1] describes demographic Data of study participants. Both group (Group A and Group B) nearly had similar mean age groups and difference between their age group was not significant statistically $(p>0.05)$ while there was statistically significant difference between weight of the both groups. $(\mathrm{p} \leq 0.05)$

[Table 2] illustrates distribution of patients according to incidence of emetic symptoms. $28.8 \%$ of patients in control group had nausea as compared to $17.7 \%$ of patients in midazolam group. Similarly, $15.5 \%$ of the patients in control group had retching as compared to $2.2 \%$ in midazolam group. $2.2 \%$ of patients in midazolam group had frank vomiting where as in control group, $31.1 \%$ of the patients had vomiting. Difference between both groups regarding emetic symptoms was found to be significant statistically $(p \leq 0.05)$. The results of our study revealed that intrathecal midazolam decrease the incidence of intra operative and early post delivery emetic symptoms in comparison with control.

[Table 3] shows Incidence of adverse effects amongst study participants. $1(2.2 \%)$ patients in group A and $4(8.8 \%)$ in group B had hypotension in our study which was not statistically significant $(\mathrm{p}>0.05)$.

Table 1: Demographic Data of study participants

\begin{tabular}{|l|l|l|l|}
\hline Demographics & $\begin{array}{l}\text { Group A } \\
\left(\begin{array}{l}\text { Mean } \pm \text { SD }) \\
\mathbf{n}=\mathbf{4 5}\end{array}\right.\end{array}$ & $\begin{array}{l}\text { Group B } \\
\left(\begin{array}{l}\text { Mean } \pm \text { SD }) ~ \\
\mathbf{n}=\mathbf{4 5}\end{array}\right.\end{array}$ & P value \\
\hline Age & $26.32 \pm 2.54$ & $25.15 \pm 2.14$ & 0.15 \\
\hline Weight $(\mathrm{kg})$ & $58.41 \pm 3.23$ & $60.32 \pm 3.01$ & $0.05^{*}$ \\
\hline
\end{tabular}

$*$ indicates statistically significance at $\mathrm{p} \leq 0.05$

Test applied student $\mathrm{t}$ test

Table 2: Distribution of patients according to incidence of emetic symptoms.

\begin{tabular}{|l|l|l|l|}
\hline $\begin{array}{l}\text { Emetic } \\
\text { symptoms }\end{array}$ & Group A & Group B & P value \\
\hline No Nausea & $39(86.6)$ & $15(33.3 \%)$ & $0.05^{*}$ \\
\hline Nausea & $08(17.7 \%)$ & $13(28.8 \%)$ & $0.001^{*}$ \\
\hline Vomiting & $01(2.2 \%)$ & $14(31.1 \%)$ & $0.003^{*}$ \\
\hline Retching & $01(2.2 \%)$ & $07(15.5 \%)$ & $0.04^{*}$ \\
\hline
\end{tabular}

* indicates statistically significance at $\mathrm{p} \leq 0.05$

Test applied chi-square test 
0

Table 3: Incidence of adverse effects amongst study participants

\begin{tabular}{|l|l|l|}
\hline Adverse effects & Group A & Group B \\
\hline Hypotension & $1(2.2 \%)$ & $4(8.8 \%)$ \\
\hline Shivering & $1(2.2 \%)$ & $5(11.11 \%)$ \\
\hline Bradycardia & 0 & 0 \\
\hline Sedation & $3(6.6 \%)$ & 0 \\
\hline
\end{tabular}

Discussion

Present study was done with an aim to evaluate the effect of intratechal midazolam for reduction in incidence of intraoperative and immediate postoperative nausea and vomiting. Multiple factors can cause nausea and vomiting during spinal anaesthesia for caesarean delivery. Hypotension may cause brain stem hypoperfusion, thus triggering emesis. Some authors recommended the prophylactic infusion of ephedrine for prevention of maternal hypotension. ${ }^{[14]}$

In the present study, the treatment groups were similar with regard to maternal demographics and operative management. Time taken and handling of viscera during cesarean section is more in multigravida with previous cesarean section which may trigger pain and emetic symptoms, thus distribution was made evenly in each group for gravid status.

$28.8 \%$ of patients in control group had nausea as compared to $17.7 \%$ of patients in midazolam group. Similarly, $15.5 \%$ of the patients in control group had retching as compared to $2.2 \%$ in midazolam group. $2.2 \%$ of patients in midazolam group had frank vomiting where as in control group, $31.1 \%$ of the patients had vomiting. Many studies concerning antiemetic effect of midazolam were performed. Splinter and colleagues showed that injection of midazolam $0.05 \mathrm{mg} / \mathrm{kg}$ after induction of anesthesia significantly reduced the incidence of nausea and vomiting similar to the same dose of droperidol in children undergoing strabismus. ${ }^{[15]}$ Bauer et al, ${ }^{[16]}$ showed that preoperative administration of midazoam $0.04 \mathrm{mg} / \mathrm{kg}$ effectively decreased incidence of PONV while increased patient satisfaction. In another study performed by Unlugenc et $\mathrm{al}^{[17]}$ it was shown that midazolam was as effective as ondansetron in treating PONV without untoward adverse effects. The prophylactic administration of midazoalm was effective in control of vomiting after tonsillectomy in children. ${ }^{[15]}$ Midazolam was effective as the antiemetic agent in patients had chemotherapy. ${ }^{[18]}$ Tarhan et al. ${ }^{[1]}$ showed that administration of a subhypnotic dose of midazoalm $1 \mathrm{mg} / \mathrm{h}$ was as effective as the subhypnotic dose of propofol $1 \mathrm{mg} / \mathrm{kg} / \mathrm{h}$ for prevention of nausea and vomiting in parturient underwent cesarean delivery under spinal anesthesia. Safavi and colleagues, ${ }^{[19]}$ found that midazolam $35 \mu \mathrm{g} / \mathrm{kg}$ administered intravenously 30 minutes before termination of surgery was more effective in decreasing the incidence of PONV than midazolam premeditation $35 \mu \mathrm{g} / \mathrm{kg}$. The mechanism of action of midazolam for prevention of emesis has not been fully understood. It is thought that midazolam decreases dopamine input at the chemoreceptor trigger zone (CRTZ) and decreases adenosine re-uptake. This leads to an adenosinemediated reduction in synthesis, release, and postsynaptic action of dopamine at the CRTZ. ${ }^{[13]}$ It may also decrease dopaminergic neuronal activity and 5HT3 release by binding to the gamma-aminobutyric acid (GABA) receptor. ${ }^{[20-23]}$

Midazolam is also an effective antiemetic in patients having chemotherapy. Unlugenc et al reported that midazolam was effective for treatment of established PONV. They also suggested that antiemetic effect of midazolam lasted longer than that of the sedative effect. ${ }^{[24]}$

$1(2.2 \%)$ patients in group A and $4(8.8 \%)$ in group B had hypotension in our study which was not statistically significant $(\mathrm{p}>0.05)$. This could be because all patients in the present study were preloaded with $15 \mathrm{ml} / \mathrm{kg}$ of Ringer lactate and wedge was provided immediately after spinal block. Total intraoperative consumption of inj. mephentermine was similar in both the groups. None of the patients required vasopressors postoperatively. Other parameters such as pulse rate and respiratory rate remained stable intraoperatively as well as post-operatively in all the patients. Therefore, in this study, the low dose of intrathecal midazolzm did not have any deleterious cardiovascular effects on the parturients. Sedation was observed only in midazolam group in $3(6.6 \%)$ patients, they were drowsy, but arousable by verbal stimulation, so no treatment was required. None of the patients in two groups developed any neurological deficits postoperatively. The results of our study are comparable to the observations in the earlier studies. ${ }^{[25,26]}$

\section{Conclusion}

Intrathecal midazolam $2 \mathrm{mg}$ with $0.5 \%$ hyperbaric bupivacaine in the subarachnoid block was effective significantly to prevent nausea and vomiting in parturient undergoing caesarean section under spinal anaesthesia. Further, studies are needed to prove the safety of midazolam in parturient undergoing caesarean section; the mothers should be observed carefully for respiratory depression and the neonates must be evaluated for any side effects.

\section{References}

1. Tarhan O, Canbay O, Celebi N, Uzun S, Sahin A, Coşkun F, et al. Subhypnotic doses of midazolam prevent nausea and vomiting during spinal anesthesia for cesarean section. Minerva Anestesiol. 2007;73:62933

2. Pan $\mathrm{PH}$, Moore $\mathrm{CH}$. Comparing the efficacy of prophylactic metoclopramide, ondansetron, and placebo in cesarean section patients given epidural anesthesia. J Clin Anesth. 2001;13:430 -5.

3. Kovac AL. Prevention and treatment of postoperative nausea and vomiting, Drugs 2000; 59: 213-43.

4. Lussos SA, Bader AM, Thornhill ML, Datta S. The antiemetic efficacy and safety of prophylactic metoclopramide for elective caesarean section delivery during spinal anaesthesia. Reg Anesth 1992; 17: 126-30.

5. Gan TJ. Postoperative nausea and vomiting-can it be eliminated? JAMA 2002; 287: 1233-6.

6. Domino KB, Anderson EA, Polissar NL, Posner KL. Comparative efficacy and safety of ondansetron, droperidol, and metoclopramide for preventing postoperative nausea and vomiting: a meta-analysis. Anesth Analg 1999; 88: 1370-9.

7. Fujji Y, Tanaka H, Kobayashi N. Prevention of nausea and vomiting after middle ear surgery: granisetron versus ramosetron, Laryngoscope 1999; 109:1988-90

8. Numazaki M, Fujii Y. Subhypnotic dose of propofol for the prevention of nausea and vomiting during spinal anaesthesia for caesarean section. Anaesth Intensive Care 2000; 28: 262-5

9. Splinter WM, MacNeill HB, Menard EA, Rhine EJ, Roberts DJ, Gould MH. Midazolam reduces vomiting after tonsillectomy in children. Can J Anaesth 1995; 42: 201-3.

10. Heidari SM, Saryazdi H, Saghaei M. Effect of intravenous midazolam premedication on postoperative nausea and vomiting after cholecystectomy. Acta Anaesthesiol Taiwan 2004; 42: 77-80.

11. Watts JC, Brierley A. Midazolam for the treatment of postoperative 
nausea. Anaesthesia 2001; 56: 1129-230.

12. Di Florio T. The use of midazolam for persistent postoperative nausea and vomiting. Anaesth Intensive Care. 1992;20:383-6.

13. Senel AC, Mergan F. Premedication with midazolam prior to caesarean section has no neonatal adverse effects. Braz J Anesthesiol. 2014;64:1621.

14. Afshari A, Møller AM, Hangaard N. Comparison of prophylactic infusion of ephedrine and phenylephrine during Caesarean section under spinal anaesthesia. Ugeskr Laeger 2006; 14: 1428-31.

15. Splinter W, Noël LP, Roberts D, Rhine E, Bonn G, Clarke W. Antiemetic prophylaxis for strabismus surgery. Can J Ophthalmol. 1994;29:224-6.

16. Bauer KP, Dom PM, Ramirez AM, O'Flaherty JE. Preoperative intravenous midazolam: Benefits beyond anxiolysis. J Clin Anesth. 2004;16:177-83.

17. Unlugenc H, Guler T, Gunes Y, Isik G. Comparative study of the antiemetic efficacy of ondansetron, propofol and midazolam in the early postoperative period. Eur J Anaesthesiol. 2003;20:668-73.

18. Olynyk J, Cullen SR, Leahy MF. Midazolam: An effective antiemetic agent for cytotoxic chemotherapy. Med J Aust. 1989;150:466.

19. Safavi MR, Honarmand A. Low dose intravenous midazolam for prevention of PONV in lower abdominal surgery--preoperative vs intraoperative administration. Middle East J Anesthesiol. 2009;20:75-81.

20. Takada K, Murai T, Kanayama T, Koshikawa N. Effects of midazolam and flunitrazepam on the release of dopamine from rat striatum measured by in vivo microdialysis. Br J Anaesth 1993; 70: 181-5.

21. Di Florio T. The use of midazolam for persistent postoperative nausea and vomiting. Anaesth Intensive Care 1992; 20: 383-6.

22. Crowe S. Midazolam: an anti-emetic? Anaesthesia 2002; 57: 830-1.

23. Bauer KP, Dom PM, Ramirez AM, O'Flaherty JE. Preoperative intravenous midazolam: benefits beyond anxiolysis. J Clin Anesth 2004; 16: $177-83$.

24. Unlugenc H, Guler T, Gunes Y, Isik G. Comparative study of the entiemetic efficacy of ondansetron, propofol and midazolam in the early postoperative period. Eur J Anaesthesiol 2004; 21: 60-5.

25. Suwalka U, Patel J and Mehta K. Postoperative analgesia with intrathecal Midazolam in caesarean section deliveries. Indian Journal of Research and Reports in Medical Sciences. 2012;2(3):1-4.

26. Shahriari A,Khooshideh M, and Heidari M. Prevention of nausea and vomiting in caesarean section under spinal anaesthesia with midazolam or metoclopramide? Journal of Pakistan Medical Association.2009;59(11):756-9.

Copyright: (๑) the author(s), publisher. Academia Anesthesiologica International is an Official Publication of "Society for Health Care \& Research Development". It is an open-access article distributed under the terms of the Creative Commons Attribution Non-Commercial License, which permits unrestricted non-commercial use, distribution, and reproduction in any medium, provided the original work is properly cited.

How to cite this article: Patel NB. Utilization of Intrathecal Midazolam for the Prevention of Nausea and Vomiting In Caesarean Section under Spinal Anaesthesia- A Prospective Study. Acad. Anesthesiol. Int. 2019;4(2):173-76.

DOI: dx.doi.org/10.21276/aan.2019.4.2.39

Source of Support: Nil, Conflict of Interest: None declared. 